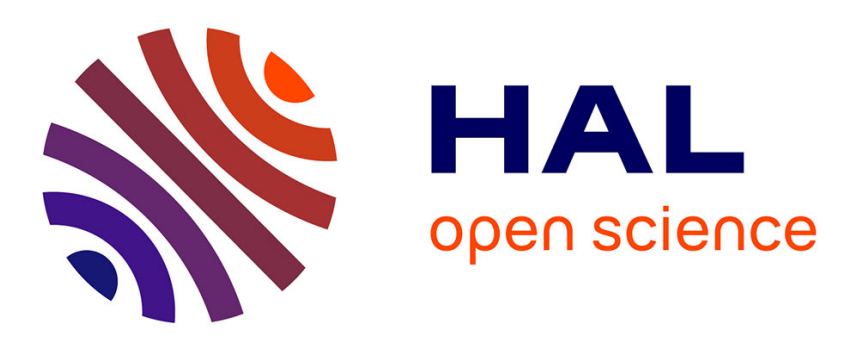

\title{
Pressure dependence of the Flory-Huggins interaction parameter in binary polymer blends investigated by SANS
}

\author{
S. Janssen, D. Schwahn, K. Mortensen, T. Springer
}

\section{To cite this version:}

S. Janssen, D. Schwahn, K. Mortensen, T. Springer. Pressure dependence of the Flory-Huggins interaction parameter in binary polymer blends investigated by SANS. Journal de Physique IV Proceedings, 1993, 03 (C8), pp.C8-17-C8-20. 10.1051/jp4:1993803 . jpa-00252222

HAL Id: jpa-00252222

https://hal.science/jpa-00252222

Submitted on 1 Jan 1993

HAL is a multi-disciplinary open access archive for the deposit and dissemination of scientific research documents, whether they are published or not. The documents may come from teaching and research institutions in France or abroad, or from public or private research centers.
L'archive ouverte pluridisciplinaire $\mathbf{H A L}$, est destinée au dépôt et à la diffusion de documents scientifiques de niveau recherche, publiés ou non, émanant des établissements d'enseignement et de recherche français ou étrangers, des laboratoires publics ou privés. 


\title{
Pressure dependence of the Flory-Huggins interaction parameter in binary polymer blends investigated by SANS
}

\section{S. JANSSEN, D. SCHWAHN, K. MORTENSEN ${ }^{*}$ and T. SPRINGER}

Forschungszentrum Jülich GmbH, Institut für Festkörperforschung, Postfach 1913, 5170 Jülich, Germany

* Risø National Laboratory, 4000 Roskilde, Denmark

\begin{abstract}
The pressure dependence of the Flory - Huggins interaction parameter of two binary polymer blends was investigated by small angle neutron scattering (SANS). We studied the polymer blends deutero - Polystyrene / Polyvinylmethylether (d - PS / PVME) and deutero Polystyrene / Polyphenylmethylsiloxane (d - PS / PPMS), exhibiting decomposition at high and at low temperatures, respectively. In both cases the enthalpic contribution of the Flory Huggins parameter is not affected by pressure in the investigated pressure range between 1 and $1200 \mathrm{bars}$, whereas the absolute value of the entropic contribution is generally a decreasing function of pressure.
\end{abstract}

\section{Theoretical Concepts}

Polymer blends follow the predictions of the mean field theory, except in the vicinity of the critical point, where, ruled by the Landau - Ginzburg criterion, a crossover to $3 \mathrm{~d}$ - Ising critical behaviour occurs [1] - [5]. In the mean field concept the Gibbs free enthalpy of mixing $\Delta G_{M}$ is given by [6]

$$
\frac{\Delta G_{M}}{R T}=\frac{\Phi}{V_{A}} \ln \Phi+\frac{(1-\Phi)}{V_{B}} \ln (1-\Phi)+\Phi(1-\Phi) \chi .
$$

Here $\Phi, V_{A}, V_{B}, R$, and $\chi$ represent the volume fraction of component $A$, the molecular volumes of the two components, the gas constant, and the Flory - Huggins interaction parameter, respectively. $\chi$ is a purely segmental quantity [6], which depends on the temperature $T$, the volume fraction $\Phi$, and on the external pressure $p$.

In a small angle neutron scattering experiment the reciprocal structure factor, extrapolated to $Q=0$ is given by

$$
S^{-1}(0)=\frac{\partial^{2}\left(\frac{\Delta G}{R T}\right)}{\partial \Phi^{2}}
$$

If we combine eqs. (1) and (2) we yield

$$
S^{-1}(0)=2\left(\Gamma_{s}-\Gamma\right)
$$


with $\Gamma_{s}=\left(\frac{1}{2 \Phi V_{A}}+\frac{1}{2(1-\Phi) V_{B}}\right) . \Gamma$ is the so called generalized Flory - Huggins parameter, which is related to $\chi$ by

$$
\Gamma=-\frac{1}{2} \frac{\partial^{2}}{\partial \Phi^{2}}(\Phi(1-\Phi) \chi)
$$

$\Gamma$ depends on the same external parameters as $\chi$ and can be written as

$$
\Gamma(T, \Phi, p)=\frac{\Gamma_{h}(T, \Phi, p)}{T}-\Gamma_{\sigma}(T, \Phi, p)
$$

with $\Gamma_{h}$ and $\Gamma_{\sigma}$, the respective enthalpy and entropy of mixing. $\Gamma_{\sigma}$ is a segmental entropy of mixing correlated to the free volume of the blend [7]. By equation of state arguments Patterson et al. [8] showed that pressure does not affect $\Gamma_{h}$, but diminishes the absolute value of $\Gamma_{\sigma}$, because the free volume gets reduced at increasing pressure. However, recent lattice cluster calculations by Dudowicz et al. [9] have shown a very weak pressure dependence of $\Gamma_{h}$.

\section{Experimental}

The neutron scattering experiments were performed at the small angle facility at the $D R 3$ reactor of the Ris $\varnothing$ National Laboratory, Denmark. A special steel bodied pressure cell was constructed, using an $\mathrm{O}$ - ring to separate the sample from the liquid hydraulic medium. We used sapphire or niobium windows, depending on the pressure required. The pressure was generated with a mechanical pressure generator obtained from NOVA SWISS, Effretikon, Switzerland. After the background subtraction the scattering data were calibrated with a Lupolen standard to obtain $S(Q)$ in absolute units.

We used the two polymer blends d - PS /PVME and d - PS /PPMS, whose characteristic data are summarized in table $\mathrm{I}$.

table I : sample characteristics

\begin{tabular}{c|c|c|c|c|c|c|c} 
blend & comp. A & comp. B & type & $V_{A}\left[\mathrm{~cm}^{3} \mathrm{~mol}^{-1}\right]$ & $u_{A}$ & $V_{B}\left[\mathrm{~cm}^{3} \mathrm{~mol}^{-1}\right]$ & $u_{B}$ \\
\hline 1 & $d-P S$ & $P P M S$ & $U C S T$ & 8800 & 1.03 & 2200 & 1.39 \\
2 & $d-P S$ & $P V M E$ & $L C S T$ & 870000 & 1.14 & 63000 & 1.98
\end{tabular}

$u_{A}$ and $u_{B}$ denote the polydispersity of the used polymers. In both cases the experiments were performed at the critical composition $\Phi_{c}$, which was $\Phi_{d-P S}=0.31$ for $\mathrm{d}$ - PS / PPMS and $\Phi_{d-P S}=0.13$ for $\mathrm{d}-\mathrm{PS} / \mathrm{PVME}$.

\section{Results and Discussion}

d - PS /PVME decomposes at high temperatures, exhibiting a lower critical solution temperature (LCST), wheras d - PS /PPMS decomposes at low temperatures (upper critical solution temperature, UCST). The decomposition in an UCST system is an enthalpy driven phenomenon, whereas in a LCST system it is due to the increasing entropy connected with an increasing free volume. Because the free volume plays a major role in LCST systems, a different pressure dependence is expected in both investigated polymer blends. The spinodal temperature $T_{s}$ is obtained for $S^{-1}(0)=0 . T_{s}$ is shown in Figure 1 as a function of pressure. One recognizes clearly that in both blends the phase boundary shifts to higher temperatures with increasing pressure. In the $\mathrm{d}$ - PS /PVME case we find a shift from $121^{\circ} \mathrm{C}$ at 1 bar to $134^{\circ} \mathrm{C}$ at $1.2 \mathrm{kbar}$ i.e. $1.2 \cdot 10^{-2} \mathrm{~K} / \mathrm{bar}$. Saturation at high pressure is visible. In the $\mathrm{d}$ - PS /PPMS case one recognizes an increase from $52^{\circ} \mathrm{C}$ at normal pressure to $56^{\circ} \mathrm{C}$ at $1 \mathrm{kbar}$ i.e. $4.3 \cdot 10^{-3} \mathrm{~K} / \mathrm{bar}$. In contrast to the former blend a shallow minimum of $T_{s}$ at 200 bars appears before increasing. 


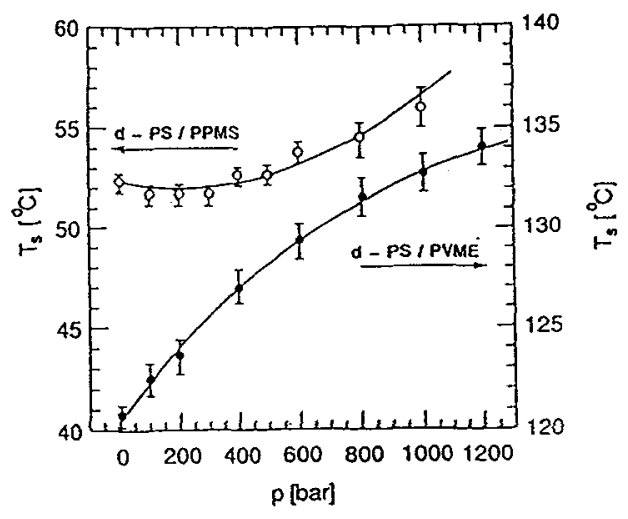

Fig. 1 : Spinodal temperatures as a function of pressure for both investigated polymer blends. In both cases the general trend is an increase of $T_{s}$ with raising pressure. The solid lines both represent fits to the data with a 2 nd order polynomial.

In the UCST system the two phase region of the phase diagram increases with raising pressure while in the LCST system the homogeneous region widens, which clearly demonstrates the different consequences of $\Gamma_{\sigma}$ on the phase boundaries in UCST and LCST polymer blends. The observed shift of the phase boundary in the $d$ - PS /PVME blend is in good quantitative agreement with cloud point measurements of Hiramatsu et al. [10] who found an increase of $T_{s}$ of $1-3 \cdot 10^{-2} \mathrm{~K} / \mathrm{bar}$, depending on the volume fraction. However, the equation of state calculation of Patterson et al. [8] gives a much larger value of $1.3 \cdot 10^{-2} \mathrm{~K} / \mathrm{bar}$ for $\mathrm{d}$ - PS /PVME.

In Figure $2 \mathrm{a}$ and $2 \mathrm{~b} \Gamma_{h}$ and $\Gamma_{\sigma}$ are plotted as a function of pressure for both systems. The pressure range of the experiments was from 1 to 600bars for $\mathrm{d}$ - PS /PPMS and from 1 to 1200bars for $\mathrm{d}$ PS / PVME. The enthalpic contribution $\Gamma_{h}$ is not affected by pressure as was expected, while the
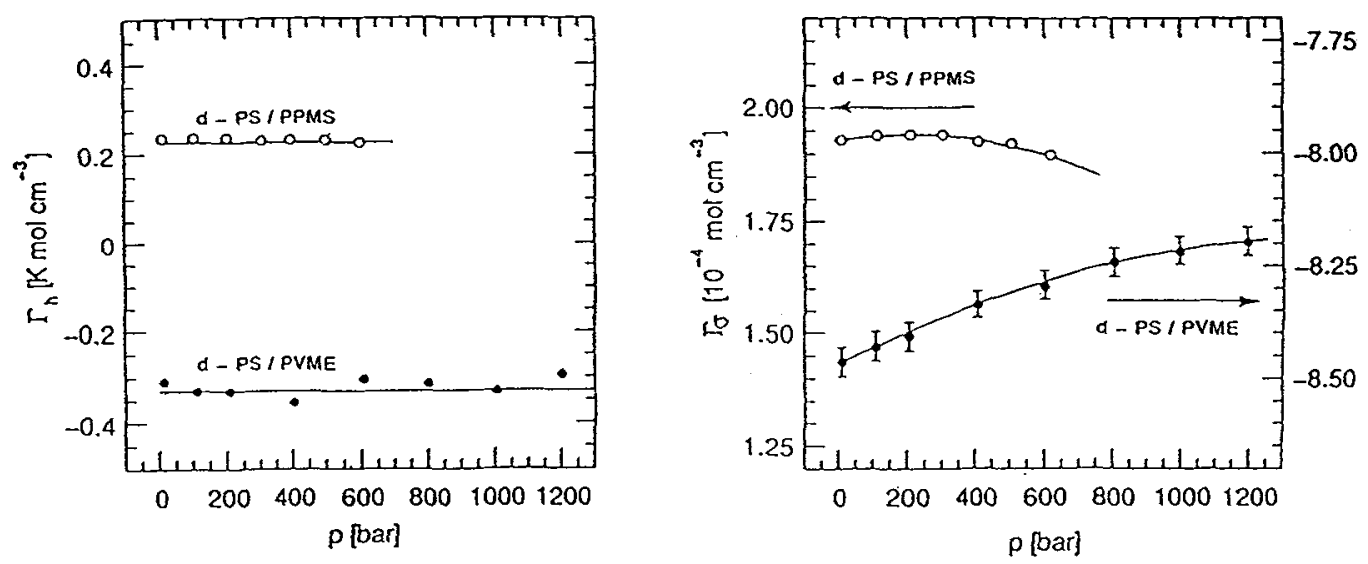

Fig. 2a,b : The enthalpic contribution $\Gamma_{h}$ (left) and the entropic contribution $\Gamma_{\sigma}$ (right) as a function of pressure for the two polymer blends in study. 
absolute value of $\Gamma_{\sigma}$ decreases with pressure for both blends. This is consistent with its relation to the free volume. Comparing both blends one recognizes differences in the behaviour of $\Gamma_{\sigma}$ as was already found for the spinodal temperatures. In the $d$ - PS / PVME case we always find a monotonous decrease of the modulus of $\Gamma_{\sigma}$ with saturation at high pressure. For d - PS /PPMS we find a shallow maximum at 200 bars and then a decrease about five times smaller than in the d - PS / PVME case.

As a whole the Flory - Huggins parameter $\Gamma$ decreases for the LCST blend $\left(\Gamma_{h}, \Gamma_{\sigma}<0\right) \mathrm{d}-\mathrm{PS} /$ PVME and increases for the UCST blend $\left(\Gamma_{h}, \Gamma_{\sigma}>0\right) \mathrm{d}$ - PS /PPMS with increasing pressure.

\section{Conclusions}

The pressure dependence of the Flory - Huggins parameter $\Gamma$ was investigated for the two binary polymer blends $d$ - PS /PPMS and d - PS /PVME by SANS. It turned out that the enthalpic contribution of $\Gamma$ is not pressure dependent in the studied pressure range up to $1200 \mathrm{bars}$, while the modulus of the entropic contribution is generally a decreasing function of pressure as a cosequence of its relation to the free volume of the blend. Future experiments at even higher pressures will show, whether the weak pressure dependence of $\Gamma_{h}$ as predicted by Dudowicz et al. [9] will be confirmed.

\section{Acknowledgements}

The neutron scattering experiments reported here were performed at the DR3 reactor at Ris $\varnothing$ National Laboratory and supported by the Commision of the European Community through the Large Installation Plan.

\section{References}

[1] Herkt - Maetzky, C.; Schelten, J.; Phys. Rev. Lett. 51 (1983) 896

[2] Schwahn, D.; Mortensen, K.; Springer, T.; Yee - Madeira, H.; Thomas, R.; J. Chem. Phys. $\underline{87}$ (1987) 6078

[3] Bates, F.S.; Muthukumar, M.; Wignall, G.D.; Fetters, L.J.; J. Chem. Phys. $\underline{89}$ (1988) 535

[4] Schwahn, D.; Janßen, S.; Springer, T.; J. Chem. Phys. 97 (1992) 8775

[5] Janßen, S.; Schwahn, D.; Springer, T.; Phys. Rev. Lett. 68 (1992) 3180

[6] Flory, P.J.; Principles of Polymer Chemistry; Cornell University Press: Ithaca, NY, 1979

[7] Janßen, S.; Schwahn, D.; Mortensen, K.; Springer, T.; subm. to Macromolecules

[8] Patterson, D.; Robard, A.; Macromolecules 11 (1978) 690

[9] Dudowicz, J.; Freed, K.F.; Macromolecules 26 (1993) 213

[10] Hiramatsu, N.; Hashida, S.; Yasuniwa, M.; Hirakawa, S.; Fukuoka Univ. Sci. Rep. 13 (1983) 39 